\title{
LA EJECUCIÓN DE UNA DECISIÓN ADMINISTRATIVA DERIVADA DE UNA ORDEN JUDICIAL, COMO FUENTE DE DAÑO ESPECIAL
}

The execution of an administrative decision derived from a court order, as a source of special damage

\section{Claudia Rosio Varela Pájaro ${ }^{9}$}

Fecha de recepción: 27 de octubre de 2017

Fecha de aceptación: 4 de diciembre de 2017

SUMARIO: 1. Introducción; 2. Aspectos que caracterizan una actuación administrativa como causal de reparación directa; 3. Efectos de la ejecución de un acto administrativo; 4 . Ejecución de una decisión administrativa en cumplimiento de un deber legal, fuente de daño especial; 5. Consideraciones finales; 6 . Referencias bibliografías

9 Abogada egresada de la Universidad de Cartagena. Especialista en Derecho Contencioso Administrativo de la Universidad Externado de Colombia. Magister en Derecho en la Universidad de Cartagena. https://orcid.org/0000-0002-0535-8488 E-mail: claudiarosiovp@hotmal.com 


\section{COMO SE CITA ESTE ARTÍCULO (APA 6)}

VARELA, Claudia Rosio (2018). La ejecución de una decisión administrativa derivada de una orden judicial, como fuente de daño especial. Revista Jurídica Mario Alario D’Filippo, Vol. X N.o 19, pág. 67 - 82

\section{RESUMEN}

El Estado colombiano en desarrollo de su función proteccionista concede al particular la posibilidad de acudir ante la jurisdicción en busca del resarcimiento de los perjuicios que sus agentes le hayan causado, sin que tuviera la obligación de soportarlos. Cuando tales perjuicios son el resultado de la ejecución de una actividad legítima de los servidores públicos, el afectado tiene la posibilidad de ejercer el medio de control de Reparación Directa, para exigir la indemnización integral del daño padecido. El daño antijurídico que padece un particular cuando un servidor público ejecuta la actividad legítima de cumplir una orden judicial, tiene por fuente la llamada Operación Administrativa. Acudir a la Jurisdicción Contenciosa Administrativa teniendo como fuente del daño una Operación Administrativa es indiferente a la presunción de legalidad del acto administrativo, pues lo que se persigue es el cuestionamiento de su ejecución o cumplimiento.

\section{Palabras Claves}

Decisión Administrativa, Daño Antijurídico, Orden Judicial, Reparación, Operación Administrativa.

\section{ABSTRACT}

The Colombian State, in developing of its protective function concedes the individuals the possibility of going to the jurisdiction, seeking compensation for the damages that its own agents have caused, without having the obligation to endure them. When such damages are the result of running a legitimate activity of public servants, the affected have the opportunity to exercise a control medium called Direct Repair to demand full compensation for the harm suffered. The damage suffered by an individual when a public servant has developed a legitimate activity, has as source the Administrative Operation. Going to the Administrative jurisdiction having as source of damage an administrative operation, is indifferent to the presumption of legality of the administrative act, because what is sought is the questioning of its execution or enforcement.

\section{Key words}

Administrative decision, damage, court order, Repair, Administrative operation 


\section{1.- INTRODUCCIÓN}

El tema propuesto hace referencia al daño antijurídico que tiene como fuente la ejecución de una decisión administrativa originada en el cumplimiento de una orden judicial que, independientemente de encontrarse ésta viciada o ser ajustada a derecho, conlleva con su acatamiento afectaciones a particulares que en oportunidades resultan predecibles pero inevitables, colocando al agente del Estado (servidor público) ante la disyuntiva de cumplir la orden judicial o de evitar la afectación al particular. Tipo de daño antijurídico que se conoce como Daño Especial.

Al igual como ocurre en las relaciones entre particulares, en que la ley ofrece mecanismos para reclamar y reparar los daños causados por el uno al otro, existen también mecanismos para reclamarle al Estado la reparación de los daños causados al particular por cualquiera de sus agentes. La diferencia entre las dos reparaciones radica en que el Estado no siempre se encuentra obligado a hacerlo, pese a la demostración de la ocurrencia del daño, su imputación y la identificación del llamado nexo de causalidad.

A cargo del Estado sólo son reparables los daños considerados antijurídicos y, la forma de su compensación o indemnización, así como el mecanismo de control jurisdiccional para conseguirla, se determinará de acuerdo a la fuente que lo origina.

El tema que es desarrollado en este artículo obliga a hacer mención de los distintos mecanismos de control con que el particular cuenta para exigirle al Estado la reparación de los daños que considere antijurídicos cuando éstos tienen su fuente en actos o decisiones administrativas, y especialmente cuando tales decisiones administrativas son el resultado del cumplimiento de disposiciones judiciales.

Si el llamado daño antijurídico es ocasionado por la ejecución de una orden, contenida en un acto administrativo, se configura una Operación Administrativa. El control por Reparación Directa que se ejercita sobre una operación administrativa, no persigue cuestionar la legalidad del acto como tal, sino su ejecución o cumplimiento.

Una modalidad de reparación por daño antijurídico que vincula al Estado es el llamado Daño Especial, sobre el que la jurisprudencia del Consejo de Estado y varios doctrinantes han sido prolijos en desarrollar. No ha sido así entratándose puntualmente del Daño Especial que interesa al tema de este artículo, y que tiene su fuente en las decisiones administrativas que son expedidas en cumplimiento de una orden judicial, sean estas ajustadas a derecho o no, causando inevitablemente daños antijurídicos que al ser previstos pudieron generar motivos de indecisión en su acatamiento, no obstante, la condición de cosa juzgada. 
Finalmente este artículo consigue, entre otras, (i) Identificar aspectos que hacen que una actuación administrativa sea considerada fuente de daño Especial, controlable como operación administrativa, mediante Reparación Directa, (ii) Diferenciar cuándo se está en presencia de un daño antijurídico causado por la ejecución de una decisión administrativa y cuándo ante uno, cuya causa es otra fuente, al establecerse los efectos de la referida ejecución; Y (iii) Ponderar el carácter obligatorio, en la toma de decisión administrativa, de cumplir una orden judicial claramente viciada, aun cuando se conoce que su ejecución causará daño antijurídico a un particular.

\section{2.- Aspectos que caracterizan una actuación administrativa como causal de reparación directa.}

Como actuación administrativa se entiende el conjunto de hechos o procederes que realizan las autoridades públicas en ejercicio de sus funciones y que conllevan para los particulares, consecuencias jurídicas por ser el resultado de la declaración de la voluntad del Estado. Atendiendo lo anterior, se tiene que de tales actuaciones administrativas interesa estudiar las iniciadas y desarrolladas por agentes del Estado en cumplimiento de una obligación o deber legal, y concretamente, las derivadas de una orden judicial.

Si bien se presume la legalidad de los actos administrativos, los efectos que se derivan de su desarrollo y ejecución resultan ser objeto de control por parte de la jurisdicción contenciosa administrativa, precisamente por tratarse de alguna manera, de una manifestación de la voluntad de la Administración. El Consejo de Estado, al referirse a la actividad de la Administración dice que,

[...] comprende múltiples facetas pero en todo caso, sin importar cuál de ellas se trate, su actuación supone la existencia de un acto administrativo, pues éste es el instrumento mediante el cual la Administración expresa su designio y cumple sus propósitos, actividad aquella que se rige no sólo por los principios constitucionales que la guían sino también por los llamados supra principios del Estado de derecho como lo son el de legalidad, el de prevalencia del interés general, el de prevalencia y respeto a los derechos fundamentales y el de control a la actividad pública, entre otros. (Consejo de Estado, 2017)

Para los efectos del presente artículo, las actuaciones administrativas que interesan son las que con su ejecución causan injustificadamente daños a una persona, frente a los cuales sólo se pretende su reparación por lo que no se cuestiona su legalidad, sino que al momento de ejercer el control de la actividad pública se confronta si ésta trasgrede, entre otros, la prevalencia del respeto a los derechos fundamentales del particular, en detrimento patrimonial de sus intereses. Se busca resarcir, por lo tanto, como lo señala Henao (1998, p 84). “la aminoración patrimonial sufrida por la víctima", cuando es víctima de un Daño Especial. 
Evaluando, así las cosas, y como lo dice Bustamante (1994. P.667), "la responsabilidad administrativa de los entes públicos por el llamado daño especial, tiene origen cuando la entidad en ejercicio legítimo de su actividad irroga daño o perjuicio a cualquier persona, en forma tal que sobrepasa o supera el ocasionado a los demás; vale decir, que con su comportamiento se rompe el principio de igualdad frente a las cargas públicas".

Una actuación administrativa será considerada causal de Reparación Directa de un daño, cuando sea realizada o provocada por un agente del Estado en ejercicio de sus funciones, o por un particular envestido de la calidad de servidor público, o por quien haya obrado conforme a encargo expreso de la Administración; $y$, además de ello, cuando esencialmente el daño infringido sea valorado como antijurídico. $\mathrm{Y}$, es que por antijurídico se entiende, todo aquel comportamiento que lesiona, vulnera o menoscaba al particular sin causa justificable. Sólo será justificable la afectación cuando el comportamiento de ese particular encuadre en un proceder legalmente reprochable, por ejemplo, si se deriva de la comisión de una conducta que se señala como punible, por la que, de ocurrir una aminoración patrimonial, no se entenderá como antijurídica, ya que será consecuencia de las cargas que ese particular estaría obligado a soportar. Tal es el caso de quien luego de ser acusado y condenado por la comisión de un hecho punible, no puede seguir laborando para generar ingresos económicos, por encontrarse privado de la libertad, o quien por orden judicial debe hacer entrega de un inmueble de su patrimonio, para cubrir los daños generados por una conducta reprochable que se le atribuye.

Del texto del artículo 90 de la Constitución Política, que dispone: "El Estado responderá patrimonialmente por los daños antijurídicos que le sean imputables, causados por la acción o la omisión de las autoridades públicas"; se desprende la obligación de dicho Estado de reparar, de resarcir al particular afectado el daño causado cuando éste no se encuentre obligado a soportarlo. Del texto del artículo 140 del Código de Procedimiento Administrativo y de lo Contencioso Administrativo, se desprende que los particulares podrán buscar la reparación de ese tipo de daño, cuando tales, tengan como causa, entre otras, una Operación Administrativa.

Ahora bien, sobre ese detrimento o aminoración patrimonial que causa al particular la trasgresión a las obligaciones del Estado, y que le atribuye a éste, el deber de responder, la Corte Constitucional se ha pronunciado diciendo:

Es claro, entonces, que la responsabilidad patrimonial del Estado en nuestro sistema jurídico encuentra fundamento en el principio de la garantía integral del patrimonio de los ciudadanos, desarrollado in extenso por la jurisprudencia y expresamente consagrado en el artículo 90 de la Constitución Política, el cual a su vez debe interpretarse en concordancia con los artículos $2^{\circ}, 13$, 58 y 83 del mismo ordenamiento superior que, por un lado, le impone a las autoridades de la República el deber de proteger a todas las personas en Colombia en su vida, honra y bienes (art. 
$2^{\circ}$ ) y, por el otro, la obligación de promover la igualdad de los particulares ante las cargas públicas (art. 13) y de garantizar la confianza, la propiedad privada y los demás derechos adquiridos con arreglo a las leyes civiles (arts. 58 y 83). (Corte Constitucional, 2011)

Visto el deber del Estado de brindarle garantías al particular en su patrimonio, se tiene que la misma providencia la Corte Constitucional también señala los aspectos para que una actuación administrativa sea objeto de control, a fin de proteger el patrimonio del particular, dice la Corporación:

Esta protección constitucional al patrimonio de los particulares se configura, entonces, cuando concurren tres presupuestos fácticos a saber: un daño antijurídico o lesión, una acción u omisión imputable al Estado y una relación de causalidad. Respecto al daño antijurídico, si bien el mismo constituye un concepto constitucional parcialmente indeterminado, en cuanto la Carta no lo define en forma expresa, la jurisprudencia y la doctrina, dentro de una interpretación sistemática de las normas constitucionales que lo consagran y apoyan, lo definen como el menoscabo o perjuicio que sufre la víctima en su patrimonio o en sus derechos personalísimos, sin tener el deber jurídico de soportarlo. En cuanto al incumplimiento del Estado, este se presenta cuando la Administración Pública no satisface las obligaciones a su cargo dentro de las circunstancias de modo, tiempo y lugar en que han sido fijadas. Finalmente, para que el daño antijurídico atribuido al Estado sea indemnizable, se exige que éste sea consecuencia del incumplimiento de las obligaciones de la Administración, esto es, desde una perspectiva negativa, que el daño sufrido por la víctima no se derive de un fenómeno de fuerza mayor o sea atribuible a su conducta negligente. (Corte Constitucional, 2011)

Concretando el tema principal de estudio, para que una actuación administrativa sea apreciada como Operación Administrativa, causal de Reparación Directa, requiere que provenga de la ejecución de un Acto Administrativo debidamente nacido a la vida jurídica, del que, como se dijo, no se cuestione su Legalidad. Como Operación Administrativa se habrá de entender el conjunto de actuaciones dirigidas a ejecutar materialmente una decisión de la administración.

Las operaciones administrativas se consideran voluntarias, dado que obedecen a manifestaciones del querer de la administración debidamente nacidas a la vida jurídica, que cumple con todos los requisitos para considerarlas legítimas, muy a pesar que se deduce de su ejecución una responsabilidad a cargo del Estado. La operación administrativa, fuente de daño antijurídico, resulta indemnizable al particular, por medio de la Reparación Directa, no obstante, sea producto de la ejecución de una actividad legítima del agente del Estado.

\section{Efectos de la ejecución de un acto administrativo.}

Como ya se dijo, el acto administrativo que interesa al presente estudio es el que produce con su ejecución un daño antijurídico al particular. Recordando la definición más conocida de daño antijurídico se tiene que es aquel que el particular no está obligado a resistir y le resulta indemnizable mediante Reparación Directa. En razón a lo anterior, es importante precisar que 
no toda ejecución de un Acto Administrativo genera daños al particular, y no todo daño generado con la ejecución de un Acto Administrativo reúne las características para ser considerado antijurídico. En el mismo orden de ideas, no toda actuación administrativa que cause daño al particular será controlable mediante Reparación Directa, habrá ocasiones en que sus efectos serán resarcidos mediante demanda de Restablecimiento del Derecho.

El Código de Procedimiento Administrativo y de lo Contencioso Administrativo en su artículo 138 habilita al particular para reclamarle al Estado cuando, con ocasión de la ejecución de una decisión administrativa, se considere lesionado en un derecho subjetivo amparado en una norma jurídica, pudiendo solicitar la reparación del daño consecuencia de dicha lesión. En igual sentido el artículo 140 del mismo estatuto normativo, señala que cuando se produce una acción u omisión por parte de agentes del Estado que cause al particular un daño, como aquel previsto por el artículo 90 de la Constitución Política, podrá éste demandar directamente su reparación.

Se observa entonces que son dos las posibilidades con las que el particular cuenta para acudir ante el Estado en pos de reclamar la reparación e indemnización de los daños extracontractuales que éste le haya causado. La de Nulidad y Restablecimiento del Derecho y la de Reparación Directa. La elección de cualquiera de los dos caminos, dependerá de la causa a la que se le atribuya el daño. Así: si la causa del daño sufrido por el particular es producto de la expedición de una decisión administrativa viciada por infringir las normas en que debía fundarse, o dictada en forma irregular, o con violación al debido proceso, entre otras, podrá ese particular hacer uso del medio de control de Nulidad y Restablecimiento del Derecho, con el fin de, luego de desvirtuar la presunción de legalidad de tal decisión, reclamar la reparación del daño que hubiera probado haber sufrido. En cambio, podrá acudir a la Reparación Directa, cuando la causa del daño padecido, corresponda a un actuar antijurídico de la Administración, que coincida con las señaladas en el artículo 140 del Código de Procedimiento Administrativo y de lo Contencioso Administrativo, es decir, cuando se trate de un hecho, una omisión, una operación administrativa - la ocupación de inmueble por cualquier causa imputable a la administración, independientemente de la intervención o no de su voluntad.

Vale hacer la aclaración que, de las causales señaladas para la procedencia del control por reparación directa, sólo la Operación Administrativa tiene origen en la ejecución de una decisión tomada por agentes del Estado, contenida en un acto administrativo como tal. Argumento este que concuerda con la temática de presente artículo.

Corresponde ahora indicar que se entiende por Operación Administrativa. El Consejo de Estado, se refiere a ella señalando: "conjunto de actuaciones orientadas a la ejecución de la decisión legal 
o administrativa, es el cumplimiento o la ejecución de los actos administrativos, son medios para darle cumplimiento a lo decidido a través de los actos administrativos" (Consejo de Estado, 2004).

Bustamante (1994, p 656) al hacer una comparación entre operación administrativa y vías de hecho, para concluir las primeras como fuente de responsabilidad administrativa, cita una sentencia de la Sala de Negocios Generales del Consejo de Estado de fecha 3 de febrero de 1964, que al definirlas dice:

[...] Para distinguirlas del simple acto escrito de la administración, se le señala como el conjunto de actos suyos a cuyo través se cumple o se quiere cumplir voluntariamente una finalidad jurídica de servicio público, y cuya causa inmediata es una decisión ora escrita, ya oral de la misma administración. Mas como de ordinario el particular sólo se entera de ella cuando va a cumplirse por la ejecución material de los actos que señalan su finalidad, es decir, los hechos culminantes del proceso, la doctrina procesal ha instruido a éstos como sujeto inmediato de la acción y permitido que para buscar el resarcimiento y hallar la fuente de la responsabilidad, baste con enjuiciar el último acto del conjunto, es decir, de la llamada operación". (Sentencia de la Sala Negocios Generales, febrero 3 de 1964)

La forma cómo son ejecutados los actos administrativos será determinante para establecer el mecanismo o vía para el resarcimiento e indemnización de los daños antijurídicos causados al particular.

El Consejo de Estado para resolver sobre la elección del medio de control procedente en un caso en el que le fueron causados perjuicios a un particular por la orden de traslado de sitio de reclusión, para lo que no se tuvo en cuenta su calidad de funcionario público, estableció que era el de Nulidad y Restablecimiento del Derecho, y con ello diferenció la noción entre acto administrativo y operación administrativa diciendo:

De tiempo atrás la doctrina y la jurisprudencia han resaltado la diferencia entre acto administrativo y operación administrativa, a partir de su misma definición:

Se entiende por acto administrativo aquella manifestación de voluntad de la administración que tiene capacidad para producir efectos jurídicos, es decir que contiene en sí mismo una decisión que puede crear o modificar situaciones, es el instrumento mediante el cual expresa su designio y cumple sus propósitos. [...]

De otro lado, operación administrativa es un conjunto de actuaciones orientadas a la ejecución de la decisión legal o administrativa, es el cumplimiento o la ejecución de los actos administrativos, son medios para darle cumplimiento a lo decidido a través de los actos administrativos.

[...]

De esta forma, mientras en una acción se persigue impugnar la validez de un acto jurídico administrativo en la otra lo pretendido es la reparación del daño causado por un hecho, una omisión, una operación administrativa, o la ocupación temporal o permanente de inmueble por causa de trabajos públicos o por cualquiera otra causa. (Consejo de Estado, 2015) 
En el caso referenciado, el Consejo de Estado decidió que la acción procedente, hoy medio de control contencioso administrativo, era la demanda de Nulidad y Restablecimiento del Derecho, debido a que el acto administrativo que ordenaba el traslado de sitio de reclusión contrariaba el ordenamiento jurídico al desconocerle al particular afectado el derecho que le asistía de ser recluido en un sitio especial, adecuado dada su calidad de exfuncionario público, lo que lo hacía violatorio de la ley.

En la referida providencia, citándose a sí mismo, el Consejo de Estado precisó: "si el daño alegado tiene como causa una decisión administrativa que el actor estima ilegal, la acción pertinente es la de nulidad y restablecimiento del derecho. [...] solo puede entenderse por operación administrativa los hechos relacionados con la ejecución material de una decisión administrativa, para efecto de interposición de una acción de reparación directa." (Consejo de Estado, 2015)

En otra situación como la anterior (Consejo de Estado, 2017), en la que igualmente se presenta la disyuntiva entre cuál medio de control aplicar, dada la afectación antijurídica al particular con la ejecución de un Acto Administrativo, el Consejo de Estado al conocer de la segunda instancia de una demanda de Reparación Directa, decide revocar la decisión del A-quo, que había considerado que el mecanismo que debía instaurar la víctima era la de Acción Electoral o la de Nulidad y Restablecimiento de Derecho, y no la de Reparación Directa que ésta en su momento instauró. En la referida demanda el particular reclamaba perjuicios patrimoniales por no haber sido posesionado en una curul en la Cámara de Representantes, siendo que los inscriptores de la lista lo habían incluido como segundo renglón de la misma, pero los agentes de la Registraduría Nacional del Estado Civil habían omitido asentarlo así en el formulario correspondiente. En el despacho de primera instancia en su momento decidió que ese era el acto administrativo que debía ser objeto de demanda, bien fuera mediante acción (hoy medio de control) electoral dentro de los veinte días siguientes al respectivo acto de elección, o por nulidad y restablecimiento del derecho, dentro de los cuatro meses posteriores al mismo; rechazando que la vía fuera la de reparación directa, por tratarse, en su criterio, de un perjuicio derivado de una actuación administrativa que no había sido impugnada y que presentaba incólume la presunción de legalidad.

El Consejo de Estado en el referido caso, revocó la decisión de primera instancia y conceptúo que lo que perseguía el particular demandante era la reparación del daño antijurídico causado por la falla del servicio ocasionada por la actuación irregular de los agentes de la Registraduría del Estado Civil y de la Cámara de Representantes que negó al particular el acceso a desempeñarse como miembro de esa Corporación y no la declaratoria de nulidad del referido acto de elección. 
Se evidencian en consecuencia las dos vías, mencionadas al inicio de este capítulo, para acudir a la jurisdicción contenciosa en busca de la reparación de un daño, la que ataca la legalidad del acto administrativo mismo y la que directamente pide su reparación, reafirmando que la escogencia del mecanismo de control procedente para la indemnización de perjuicios al particular, se deriva de la causa que lo origina.

\section{4.- Ejecución de una decisión administrativa en cumplimiento de un deber legal, fuente de daño especial.}

El artículo 40 del Código de Procedimiento Administrativo y de lo Contencioso Administrativo al señalar las formas como se inicia la actuación administrativa, establece que habrá de ser: (i) Por quienes ejerciten el derecho de petición, en interés general, (ii) Por quienes lo ejerciten en interés particular, (iii) Por quienes obren en cumplimiento de una obligación o deber legal; y (iv) oficiosamente. Para efectos del presente estudio interesan las actuaciones administrativas que surgen a partir del cumplimiento de una obligación o deber legal, concretamente las que tienen origen en una orden judicial, cuya ejecución causa daño a un particular.

A los actos administrativos que dan cumplimiento a una orden judicial se les conocen como de Ejecución, y en principio no son objeto de control por parte de la jurisdicción contenciosa administrativa, salvo que causen un daño extracontractual, el que, por provenir de una actividad legítima de la Administración, toma el nombre de Daño Especial y será controlable mediante acción de reparación directa.

Es conveniente mencionar, atendiendo el tema de estudio, que la acusación de un daño extracontractual por parte de la Administración no se justificará o excusará alegando que la decisión administrativa tuvo origen en una orden emitida por autoridad judicial competente, puesto que lo que se cuestiona y hace antijurídico el perjuicio es la condición de irresistible de la afectación al particular.

Otra excepción a la improcedencia de control jurisdiccional a actos de ejecución fue identificada por el Consejo de Estado en providencia de 2011, señalando:

[...] esta corporación ha aceptado una excepción consistente en que, si bien los actos administrativos de ejecución no son demandables, si la administración al proferirlo se aparta del verdadero alcance de la decisión o de las súplicas del actor, [...] agregándole o suprimiéndole algo, resulta incuestionable que el acto no es de simple ejecución como quiera que nace a la vida jurídica un nuevo acto administrativo que sería a todas luces controvertible ante la jurisdicción. [...] Lo anterior conlleva a concluir que con la expedición del acto administrativo demandado se genera un hecho nuevo no decidido en la sentencia a la que se está dando cumplimiento, es decir, existe una situación jurídica nueva no discutida ni definida en el fallo. Entonces, como lo que motivó la nueva demanda de nulidad y restablecimiento del derecho, fue el no 
pronunciamiento sobre la referida pretensión que en últimas es el objeto del acto acusado, se observa que ello comprende un hecho nuevo que amerita control jurisdiccional. (Consejo de Estado, 2011)

\subsection{Efectos de la no ejecución de orden judicial.}

La Constitución Política colombiana señala que los servidores públicos son responsables por la omisión en el ejercicio de sus funciones (Art. 6을 y encarga al Ministerio Público la tarea de vigilar que estos cumplan, entre otras, las decisiones judiciales (Art. 277.1). El incumplimiento de una providencia judicial quebranta el ordenamiento jurídico en la medida que afecta derechos fundamentales del beneficiario de la misma.

No obstante, lo anterior, pueden presentarse eventos en los que el Agente de la Administración perciba que al atender el cumplimiento de una determinada orden judicial afectará al particular a quien van dirigidos sus efectos, que no necesariamente es el beneficiario de la providencia judicial, sin embargo, no le está dado evitarlos, precisamente por tener el deber legal de acatarla.

La Corte Constitucional ha previsto situaciones en la que el servidor público incumple una orden judicial, identificando, en providencia de tutela, aquellas en las cuales existe imposibilidad física y jurídica para dar cumplimiento a la orden original de un fallo judicial (Corte Constitucional, 2013), al respecto dijo:

La explicación sobre el alcance y sentido del cumplimiento de los fallos judiciales, como parte del derecho fundamental al acceso a la administración de justicia, estaría incompleta si no se hace referencia a aquellos casos en que no se presentan los elementos fácticos o jurídicos necesarios para cumplir la orden original del fallo. Debe aclararse que no se trata de eventos en que se avale el incumplimiento de la orden judicial proferida; por el contrario, con el ánimo de alcanzar la satisfacción material del derecho involucrado, por encima de obstáculos formales que en su ejecución se encuentren, se han previsto formas alternas de cumplimiento del fallo que busquen la satisfacción del derecho al acceso a la administración de justicia siempre que la obligación original se aprecie como de imposible realización.

Para estos casos, la Corte Constitucional ha exigido, en primer lugar, la necesidad de probar, por la parte accionada, de forma eficiente, clara y definitiva la imposibilidad física o jurídica de llevar a cabo la orden original; $y$, como segundo elemento configurador de la situación, ha previsto el empleo de vías alternas para la satisfacción de los intereses del titular del derecho protegido en el fallo judicial, las cuales permitan equiparar sus consecuencias al cumplimiento de la orden judicial original, llegando, de esta forma, a la satisfacción material del derecho fundamental de acceso a la administración de justicia.

Según la cita, el servidor público puede justificar el incumplimiento de una orden judicial, cuando demuestre la incapacidad física y material para acatarla y, a la vez, ofrezca al titular una forma de ejecución alterna igual de satisfactoria a lo ordenado inicialmente por el fallo judicial. Estos 
requisitos pueden ser de difícil concurrencia, bien sea por dificultad en la prueba o por imposibilidad de ofrecer una ejecución alternativa, en estos casos no le quedará otro camino al servidor que cumplir la orden judicial, y en ocasiones a sabiendas que puede causar un daño a un particular distinto al beneficiario de la orden original.

\subsection{Cumplimiento de un deber legal, fuente de Daño Especial.}

La jurisprudencia ha sido reiterativa en identificar la existencia de un Daño Especial, cuando concurren tres elementos: (i) una actividad legítima de la Administración; (ii) la ruptura en cabeza de un particular del principio de igualdad frente a las cargas públicas y (iii) la existencia de un nexo causal entre la actuación de la Administración y el rompimiento de esa igualdad.

Como se desarrolló en el aparte anterior es deber legal de la Administración dar cumplimiento a las decisiones judiciales, evitando incurrir en el quebrantamiento del ordenamiento jurídico que implique la afectación de derechos fundamentales, no obstante, tal cumplimiento de deber legal, tal actividad legítima de la Administración puede a su vez causar perjuicios a otros particulares no intervinientes en el trámite judicial, y por tanto sin la obligación de soportarlos. Bustamante $(1994,665)$ resalta que "La actuación de la Administración puede ser plenamente lícita, legal desde todo punto de vista y no obstante causar lesionamiento a los administrados. En este evento el Estado también debe indemnizar la totalidad de los perjuicios producidos." Sostiene ese autor que la tesis de la responsabilidad del Estado por daño especial está fundamentada en la igualdad que frente a las cargas públicas deben tener los gobernados, impuestas conforme al principio de equidad y justicia distributiva, y que cuando el Estado rompe con esa igualdad, haciendo más oneroso el compromiso social a unos que a otros, incurre en una injusticia que debe reparar en todas sus consecuencias. (Bustamante 1994, 665)

\subsection{Incapacidad de la Administración para ponderar conflictos entre bienes jurídicos de particulares, a la hora de dar cumplimiento a una orden judicial.}

Resulta ser un tema novedoso a la hora de resolver conflictos entre principios o entre derechos fundamentales, el que la Jurisdicción acuda a la Ponderación, la que, como lo dice Estrada-Vélez (2010, p.83) se puede describir como el procedimiento dirigido a determinar, dadas unas circunstancias específicas, el mayor peso de un principio frente a otro. Motivado de alguna forma en la necesidad de satisfacción de ambos derechos.

Actualmente en Colombia no le es permitido al agente de Estado oponerse al cumplimiento de una orden judicial no obstante sea evidente que con la ejecución de la decisión administrativa que disponga tal cumplimiento, se iría a transgredir un derecho fundamental del particular titular del bien jurídico sobre el cual recaerá la misma, o sobre otra persona. 
El siguiente caso ejemplariza el fundamento de la afirmación anterior, y es tema central del presente artículo: (i) La señora Teresa Mejía ocupó el primer lugar de la lista de elegibles de una convocatoria pública para proveer empleos. Atendiendo a razones personales manifestó a la Entidad convocante su voluntad de renunciar al cargo; (ii) La Entidad consideró que antes de pronunciarse sobre la renuncia de la concursante, debía agotar las etapas de nombramiento y notificación del acto administrativo respectivo, atendiendo que sólo hasta ese momento sería la oportunidad para que fuera manifestada la aceptación o no del empleo; (iii) Mientras se producía la expedición del acto administrativo de nombramiento y transcurría el tiempo de aceptación del mismo, el concursante que ocupó el segundo reglón de la lista solicitó ser nombrado en el cargo, y al no recibir respuesta instauró Acción de Tutela en contra de la Entidad y de la Comisión Nacional del Servicio Civil (que dirigió el concurso de mérito). (iv) El Juez de primera instancia de la Acción de Tutela decidió no tutelar el derecho, al recibir el informe de que el nombramiento de la señora Teresa Mejía apenas había sido notificado y que estaba en curso el término de diez días, para que aquella manifestara su aceptación o no. (v) Este fallo de tutela fue impugnado, y el Juez de segunda Instancia resolvió tutelar el derecho, fundamentado en la renuncia inicial de la señora Mejía, sin verificar que, con posterioridad al acto de Nombramiento, ésta había decidido aceptar el cargo, tomado la debida posesión y, a la fecha de dicho fallo, ya llevaba tres meses ejerciéndolo. (vi) En el trámite de la Acción de Tutela la señora Teresa Mejía no fue convocada a participar como Tercero con interés, por lo que no tuvo conocimiento que se estaba discutiendo sobre su derecho, circunstancia que podría considerarse como un vicio o error judicial, pues de haber sido llamada y escuchada, otro hubiera sido el resultado de la decisión final.

La entidad que había convocado a concurso público de mérito recibió la orden judicial de revocar el acto administrativo de nombramiento, siendo la señora Teresa Mejía injustamente retirada del cargo, lo que le causó un daño que no estaba obligada a resistir, y aun cuando pudo haber sido previsto por el Agente del Estado, éste no tuvo la posibilidad de evitarlo pese a que era evidente que hubo un error de apreciación en el fallo de segunda instancia, esta situación puso a la Administración ante un conflicto entre dos derechos fundamentales, el adquirido meritoriamente y el reconocido por sentencia judicial, debiendo en consecuencia decidirse por el segundo sin otra consideración que el deber legal de cumplir el mandato judicial, so pena de incurrir en falta disciplinaria y ser acusado del delito de Prevaricato o de Fraude a Resolución Judicial.

Con la ejecución de la decisión administrativa que daba cumplimiento a la orden judicial se causó un Daño Especial al particular, entre otras razones porque separó a Teresa Mejía de un cargo que había obtenido meritoriamente, tras ocupar el primer puesto en la lista de elegibles de un concurso público, derivándose una Operación Administrativa controlable únicamente mediante Reparación Directa, en busca de su indemnización o compensación. 
En situaciones como la descrita, que conveniente sería si el agente ejecutor hubiera tenido la posibilidad de actuar con discrecionalidad frente a la orden judicial, ponderando los efectos de su cumplimiento de la misma forma como lo hace el dispensador de justicia cuando se encuentra frente a un conflicto entre derechos fundamentales; en este caso, el derecho de quien había adquirido el derecho a ocupar un cargo público mediante concurso público de mérito y el de quien lo había adquirido por decisión judicial.

Sin desconocer que la institución de la llamada Seguridad Jurídica dentro Debido Proceso, surge, entre otras, como freno a arbitrariedades originadas precisamente en la discrecionalidad de quienes deben acatar los fallos judiciales; adquiere igual relevancia el que dicho ejecutor tenga la potestad de ponderar la eficacia de la respectiva orden judicial frente a la afectación de derechos fundamentales derivados de valores superiores del particular que tiene que soportar los efectos, siendo ajeno a tal obligación, cuando concurran elementos que hagan prever la ocurrencia de un daño especial. Utópico o real, lo anterior contribuiría a una mejor distribución del rublo presupuestal destinado para cubrir las consecuencias patrimoniales de las reparaciones a cargo del Estado.

\section{CONSIDERACIONES FINALES}

A la pregunta problema de si ¿Constituye fuente de daño antijurídico, la ejecución de una decisión administrativa que causa perjuicio a un particular, originada en el cumplimiento de una orden judicial, sea ésta viciada o ajustada a derecho? Se le responderá afirmativamente, dado que entre los fines del Estado se encuentra la salvaguarda de los intereses (vida, honra y bienes) del particular, como lo contiene el artículo 2ㅇ de la Constitución Política, y en fin la garantía del respeto a los derechos adquiridos, que le genera la confianza en el resarcimiento o indemnización de los perjuicios cuando no se encuentra obligado a soportarlos.

Habiendo sido uno de los objetivos específicos del proyecto desarrollado, "el establecer la incidencia del cumplimiento de una orden judicial en la ejecución de una decisión administrativa que causa un daño antijurídico a un particular, a fin de determinar la carga y procedencia del medio de control jurisdiccional para su reparación"; se tiene que no obstante la decisión administrativa, que atiende el cumplimiento de una orden judicial, se encuentra contenida en un acto administrativo, su control se hará mediante demanda de Reparación Directa, al perseguirse sólo la reparación patrimonial del perjuicio.

La forma de reparación del daño por la ejecución de una operación administrativa se distingue de la que se presenta por la expedición de un acto administrativo, en que para que la segunda prospere se requiere la declaratoria de ilegalidad de la actuación administrativa, en cambio que, para la primera, solo se requiere demostrar la antijuridicidad del perjuicio que genera. 
Fuerza concluir que toda actuación administrativa debidamente nacida a la vida jurídica, en la que se hallen cumplidos los requisitos exigidos para su legalidad, será de obligatorio cumplimiento, no obstante, su ejecución cause a su destinatario un perjuicio, que, al ser calificado de antijurídico, deberá ser reparado por el Estado en acatamiento de lo normado en el artículo 90 de la Constitución Política.

Cuando el daño provenga del cumplimiento por parte del Estado de un deber legal, no habrá excusa para no repararlo, constituyéndose en un daño especial, toda vez que obedece al desequilibrio del particular frente las cargas públicas.

Llama la atención que el agente de la administración pese a que en determinada ocasión pueda percibir la afectación a un particular, con la ejecución de una decisión judicial, no tenga la potestad para abstenerse de darle cumplimiento, ni pueda en desarrollo de la discrecionalidad, ponderar entre los derechos o principios fundamentales participantes en el acatamiento de dicha decisión. Deduciéndose en consecuencia el deber de repararlo, por tratase de la ocurrencia de un daño especial.

\section{REFERENCIAS BIBLIOGRAFÍAS}

BUSTAMANTE A. (1994) Derecho Administrativo Colombiano, Tomo II. Bogotá, Editora Jurídica de Colombia

ESTRADA-VÉLEZ, S. (2010) “LA PONDERACIÓN O LA DÉBIL FRONTERA ENTRE LA ARBITRARIEDAD Y EL USO LEGÍTIMO DE LA DISCRECIONALIDAD” Universitas, núm. 121, julio-diciembre, 2010, pp. 77-111Pontificia Universidad Javeriana Bogotá, Colombia

HENAO J. (1998) El Daño Bogotá. Externado de Colombia. Bogotá (1998)

(Consejo de Estado, 2004) Consejo de Estado, Sección Primera, Consejero Ponente: Gabriel Eduardo Mendoza Martelo, Bogotá agosto 26 de 2004, rad 66001-23-31-000-2000-0057-01

(Consejo de Estado, 2009) Consejo de Estado. Sala de lo Contencioso Administrativo. Consejero Ponente: Ramiro Saavedra Becerra. Bogotá, 11 de febrero de 2009.

(Corte Constitucional, 2011) Corte Constitucional, Sentencia C- 644/11 Magistrado Ponente: JORGE IVÁN PALACIO PALACIO Bogotá D. C., treinta y uno (31) de agosto de dos mil once (2011) expediente D-8422 Demanda de inconstitucionalidad contra los artículos 140 (parcial) y 144 (parcial) de la Ley 1437 de 2011. 
(Consejo de Estado, 2011) Consejo de Estado Sala de lo Contencioso Administrativo Sección Segunda Subsección " $A$ " Consejero Ponente: Dr. ALFONSO VARGAS RINCON Bogotá DC; abril siete (07) del año dos mil once (2011) Radicación número: 25000-23-25-000-2010-00152-01(14952010)

(Corte Constitucional, 2013) Corte Constitucional Sentencia T-216/13 Magistrado Ponente: ALEXEI JULIO ESTRADA Bogotá D.C., diecisiete (17) de abril de dos mil trece (2013)

(Consejo de Estado, 2015) Consejo de Estado. Sección Tercera Subsección Consejera Ponente: OLGA MELIDA VALLE DE LA HOZ de enero 28 de 2015. Rad.: 25000-23-26-000-2004-0068001(32573)

(Consejo de Estado, 2017) Consejo de Estado, Sección Tercera, C.P. JAIME ORLANDO SANTOFIMIO GAMBOA, Sentencia de mayo 18 de 2017. Rad. 66001-23-31-000-2002 00752-02 (32736) 